\title{
Práticas pedagógicas no ensino superior: uma abordagem a partir da unidade curricular de Iniciação à Leitura e à Escrita
}

\author{
João Paulo Balula \& Dulce Melão
}

\begin{abstract}
Resumo:
Neste artigo refletimos sobre o papel de estudantes e de docentes no século XXI, à luz das práticas pedagógicas desenvolvidas, ao longo de dez anos, no âmbito da unidade curricular de Iniciação à Leitura e à Escrita da licenciatura em Educação Básica. Partindo de um enquadramento teórico que contempla a pedagogia para a autonomia e a importância da leitura e da escrita no seu âmbito, traçamos os seguintes objetivos: i) refletir sobre a relação estabelecida entre os conteúdos programáticos da unidade curricular de Iniciação à Leitura e à Escrita e a sua articulação com as práticas pedagógicas implementadas; ii) indagar o contributo da literatura para a infância no âmbito da construção de uma pedagogia para a autonomia, nomeadamente no que concerne ao conciliar do trabalho autónomo dos estudantes com o trabalho desenvolvido em sala de aula. Concluímos que os percursos realizados nos possibilitaram escutar, de forma crescente, os estudantes, sendo a investigação levada a cabo no âmbito dos itinerários percorridos um auxílio importante para a renovação das nossas práticas pedagógicas. Em tal renovação, destacaram-se os percursos de leitura propostos, procurando, em permanência, reconstruí-los enquanto partilha que possibilitasse, aos estudantes e aos docentes, habitar, de modo renovado, exercícios de cidadania cada vez mais complexos.
\end{abstract}

Palavras-chave:

práticas pedagógicas; ensino superior; leitura; cidadania. 


\title{
Pedagogical practices in higher education: an approach from the curricular unit of Reading and Writing Initiation
}

\begin{abstract}
The aim of this paper is to look into the role of students and teachers in the XXI century, in the light of the pedagogical practices developed, over ten years, within the scope of the curricular unit of Reading and Writing Initiation of a bachelor's degree in Education. Drawing from a theoretical framework encompassing pedagogy for autonomy and the role played by reading and writing within the scope of such practices, we aim to: i) reflect on the relationship between the syllabus of the curricular unit of Reading and Writing Initiation and its articulation with the pedagogical practices implemented; ii) examine the contribution of children's literature regarding the reconstruction of a pedagogy for autonomy, namely concerning the articulation of students' autonomous work with classroom practices. We conclude that the paths we followed have enabled us to increasingly listen to the students, and the research that we have been carrying out in these courses is an important aid for the renewal of our pedagogical practices. In this renovation, the proposed reading pathways stood out as means of sharing, contributing to allow students and teachers to embrace, in a transformed way, the increasingly complex practice of citizenship.
\end{abstract}

Keywords: pedagogical practices; higher education; reading; citizenship.

\section{Pratiques pédagogiques dans l'enseignement supérieur : l'apport de l'unité curriculaire d'Initiation à la Lecture et à l'Écriture}

Résumé: Dans cet article, nous examinons le rôle des étudiants et des enseignants au XXle siècle, à la lumière des pratiques pédagogiques développées au cours des dix dernières années, dans l'unité curriculaire d'Initiation à la Lecture et à l'Écriture, dans le cadre d'un diplôme en éducation. Partant d'un cadre théorique envisageant la pédagogie de l'autonomie et le rôle joué par la lecture et l'écriture dans le cadre de telles pratiques, nous traçons les objectifs suivants: i) réfléchir sur la relation établie entre le programme de l'unité curriculaire de Initiation à la Lecture et à l'Écriture et son articulation avec les pratiques pédagogiques développées; ii) étudier l'apport de la littérature pour l'enfance dans le cadre de la reconstruction d'une pédagogie de l'autonomie, notamment en ce qui concerne la conciliation du travail autonome des étudiants avec le travail développé en classe.Nous concluons que les chemins parcourus nous ont permis d'écouter de plus en plus les étudiants et que les recherches que nous avons menées dans ces cours ont constitué une aide importante pour le renouvellement de nos pratiques pédagogiques. Dans cette rénovation, les chemins de lecture reconstruis ont acquis une importance particulière, permettant aux étudiants et aux enseignants d'embrasser, de manière renouvelée, des pratiques de la citoyenneté, de plus en plus complexes.

Mots-clés: pratiques pédagogiques; enseignement supérieur; lecture; citoyenneté.

\section{Prácticas pedagógicas en la enseñanza superior: un abordaje a partir de la unidad curricular de Iniciación a la Lectura y la Escritura}

Resumen En este artículo tenemos como objetivo reflexionar sobre el papel de los estudiantes y profesores en el siglo XXI, a la luz de las prácticas pedagógicas desarrolladas en el curso de Iniciación a la Lectura y la Escritura, a lo largo de diez años, en el grado en Educación Básica. A partir de un marco teórico contemplando la pedagogía para la autonomía y el papel de la lectura y de la escritura en el ámbito de tales prácticas, trazamos los siguientes objetivos: i) reflexionar sobre la relación establecida entre los contenidos programáticos de la unidad curricular de Iniciación a la Lectura y la Escritura y su articulación con las prácticas pedagógicas implementadas; ii) indagar la contribución de la literatura para la infancia en el ámbito de la reconstrucción de una pedagogía para la autonomía en particular en lo que concierne al conciliar del trabajo autónomo de los estudiantes con el trabajo desarrollado en el aula. Concluimos que los recorridos realizados nos permitieron escuchar de forma creciente a los estudiantes, siendo la investigación que fuimos efectuando en el marco de tales recorridos una ayuda importante para la renovación de nuestras prácticas pedagógicas. En esa renovación se destacaron los itinerarios de lectura propuestos, buscando, en permanencia, reconstruirlos en cuanto ato de compartir que posibilitara, a los estudiantes y a los docentes, abrazar, de modo renovado, ejercicios de ciudadanía cada vez más complejos.

Palabras clave: prácticas pedagógicas; enseñanza superior; lectura; ciudadanía. 


\section{Introdução}

Não por acaso, no espaço liminar em que o paratexto se reconstrói e transborda do branco imenso da página, a aprendizagem é encarada pelo artesão da palavra, o poeta, numa multidimensionalidade ao mesmo tempo precária e sorridente que aqui justifica a sua menção. Assim, em Vertentes do olhar (Andrade, 2016), Eugénio de Andrade, numa quase epígrafe, ensina-nos que «desaprender custa mais do que aprender» (Andrade, 2016, s/p), oferecendo-nos caminhos que, porventura, nos convidam a rever as nossas práticas pedagógicas partilhadas com estudantes futuros profissionais da Educação. De forma distinta, mas ainda muito bela, Ondjaki toca a palavra «aprendizagem» de modo a que nela ecoe o abraço ao Outro quando nele o percorre, pois, em seu entender, "(...) ela enlaça, abraça, mastiga um alguém cuspindo-o a si mesmo, tudo para novas géneses pessoais» (Ondjaki, 2008, s/p).

No diálogo aqui convocado pelos dois poetas entretecemos, também, o que Sá-Chaves (2007) entende enquanto «(...) efeito multiplicador do diverso trazendo à visão singular de cada sujeito investigador o espelhamento multifacetado das visões também únicas e (por isso preciosas) de cada outro» (Sá-Chaves, 2007, p. 21), num bailado de olhares que se cruzam, se interrogam e se enriquecem no compromisso estabelecido entre quem ensina e quem aprende (num movimento de reciprocidades, sempre inacabadas, entre a formação e a transformação).

Face ao referido, ao longo do artigo, após o enquadramento teórico que acomoda o alinhamento traçado em demanda de inquietações que possam dar maior fôlego aos nossos propósitos, procuramos: i) traçar um breve historial e evolução dos conteúdos programáticos da unidade curricular de Iniciação à Leitura e à Escrita, de forma a esclarecer o seu contributo sobre o papel do estudante e do docente no século XXI; ii) relacionar tais conteúdos programáticos com as práticas pedagógicas implementadas em contexto de sala de aula, bem como a sua articulação com o trabalho autónomo do estudante; iii) indagar o contributo da literatura para a infância, mormente do livro-álbum, no seu cruzamento com os conteúdos programáticos relativos à leitura, no âmbito da unidade curricular acima referida, para a reconstrução de percursos de conjugação do trabalho autónomo dos estudantes com a dimensão teórico-prática desenvolvida em contexto de sala de aula.

\section{Enquadramento teórico}

No âmbito desta reflexão, entendemos a Educação «(...) como processo individual de aperfeiçoamento, como itinerário pessoal que se serve de todas as ocasiões para progredir e tem em cada pessoa um caminho único e uma singularidade própria» (Boavida, 2013, p. 29) e também, de forma marcada, enquanto caminhada solidária que 
acolhe a «capacidade de ser para os demais» (Maia, 2013, p. 61), implicando-nos, em permanência, no labor da generosidade.

No exposto no parágrafo anterior inscreve-se o enquadramento teórico deste artigo, contemplando a pedagogia para a autonomia, considerada enquanto projeto pedagógico «(...) sempre inacabado e que se vai construindo à medida que professores e alunos se interrogam acerca do que (não) faz sentido na educação» (Vieira, 2014, p. 25). Em tal âmbito, os aprendentes e os professores são encarados enquanto «(...) critical (rather than passive) consumers and creative producers of knowledge, co-managers of teaching and learning processes, and partners in pedagogical negotiation» (Raya, Lamb \& Vieira, 2017, p. 21), adotando um posicionamento reflexivo enquanto condição fundamental para o compromisso com o Outro, sendo reconstruídos percursos de cidadania plurais e diversificados (Bugallo-Rodríguez \& Naya-Riveiro, 2018). Tal compromisso é exigido, de forma crescente, no âmbito das reconhecidas mudanças na arena educativa, propiciadas pelos desafios pós-Bolonha (Leite \& Ramos, 2014; Ramos et al., 2013) e apontadas em relatórios internacionais (por exemplo, OECD, 2018a; 2018b), focando o papel dos professores do ensino superior, como ilustra o seguinte excerto: «(...) higher education teachers (...) need to co-operate with students, colleagues from other departments, and with external stakeholders as members of a dynamic learning community» (Hénard \& Roseveare, 2012, p. 9).

Na sua conhecida obra Pedagogia para a autonomia. Saberes necessários à prática educativa, Freire (2002) ensina-nos a importância da reflexão crítica sobre a prática, bem como da consciência do inacabamento enquanto condição fundamental para que possamos acolher o inusitado que vem ao nosso encontro. De particular relevo para a nossa reflexão, é o seu entendimento quer da autonomia, quer da escuta na prática educativa, cujas ramificações e entrelaçamentos consolidam modos de encarar a forma como nos posicionamos na Educação. Para Freire (2002), ensinar exige «saber escutar», num processo pautado pelo cuidado implícito no que entende enquanto estímulo ao acolhimento do «tempo de quem escuta» que abrigue silêncios que possam ser entretecidos de indagações e de dúvidas. Assim, «Escutar é obviamente algo que vai mais além da possibilidade auditiva de cada um (...) significa a disponibilidade permanente por parte do sujeito que escuta para a abertura à fala do outro, ao gesto do outro, às diferenças do outro» (Freire, 2002, s/p).

Ensinar implica também mobilizar a leitura e a escrita. Na Sociedade do Conhecimento, a informação pode obter-se facilmente, mas é necessário proceder de forma eficaz à sua seleção, processamento e avaliação de modo a construir conhecimento que sustente a ação. Como refere Balula (2011, p. 22), «é o conhecimento que permite aproveitar o potencial do mundo virtual para conseguir as mudanças estruturais que a sociedade reclama, que permite transformar a informação em eficiência e produtividade». 
Ao longo dos tempos, a escrita foi um meio de organização social e comercial, serviu propósitos religiosos, sagrados ou de adivinhação, teve também fins políticos. Não se escrevia necessariamente para se ler. Na Grécia Antiga, a escrita tornou-se depositária do pensamento de alguém para ser conhecido por outras pessoas. A escrita e a leitura possibilitam, assim, a transmissão de saber e a relação com o conhecimento do passado e do presente. Há, na leitura, uma partilha de saber e de conhecimento que ora se aceita, ora se recusa, ora se problematiza.

Desde muito cedo que a leitura é uma atividade social. Lê-se em conjunto: os pais com os filhos, os educadores com as crianças, os avós com os netos, etc. Segundo Marôco (2018, p. 125), "O efeito de atividades precoces de literacia, como por exemplo a leitura frequente de livros em casa, (...) tem sido confirmada» em estudos internacionais como muito vantajoso. A proximidade e o envolvimento que se criam nestes momentos de leitura são fundamentais.

A formação de leitores conta com a intervenção de fatores de índole social, pessoal e política. No seu âmbito, interessa-nos destacar o papel dos professores, uma vez que a sua ação «é um elemento chave na aquisição das competências fundamentais de que o aluno necessita para compreender o que lê, para estudar, para obter sucesso académico» (Trindade, 2009, p. 292), podendo inibir outros fatores associados ao insucesso na escola.

Por outro lado, o aparecimento das tecnologias da informação e da comunicação coloca-nos novos desafios que advêm das vantagens e das indagações suscitadas por um novo suporte a partir do qual se lê: o ecrã. A escola não pode ignorar esta realidade, mas sim integrá-la plenamente, «de modo a que página e ecrãs convivam de forma profícua no quotidiano escolar, favorecendo e consolidando hábitos de leitura» (Melão \& Balula, 2012, p. 240).

Reconhecida a importância dos saberes e das representações das crianças sobre o sistema alfabético de escrita, é fundamental que elas tenham acesso a um ambiente em que Ihes seja proporcionado um conjunto de materiais, atividades e experiências de qualidade que terão um papel importante no sucesso relativamente à aprendizagem da leitura e da escrita. Neste âmbito, como afirma Colomer (2010, p. 93), «la literatura es un gran instrumento de ayuda para enfrentar los cambios sociales».

São muitas as evidências da importância do papel assumido pela leitura de contos no desenvolvimento da alfabetização emergente das crianças. Os livros e as histórias contribuem para potenciar o seu desenvolvimento antes de aprenderem a ler. O espaço familiar oferece possibilidades inigualáveis que contribuem para o processo de formação de leitores uma vez que pode apresentar a leitura sem obrigações nem exigências, como algo que se desfruta durante o tempo de ócio, algo que, através da palavra, reforça os afetos e convida a partilhar emoções. Como concluem Caride, 
Caballo e Gradaílle, (2018, p. 15), a leitura contribui para que sejamos «personas más críticas, responsables y conscientes; y, por ello, tal vez más libres».

Diversos autores (por exemplo, Balula, 2011; Morais, 2012; Sousa, 2015; Trindade, 2009; Sousa, 2015) destacam a importância, quer em termos escolares, quer para a vida ativa, do ensino explícito de estratégias específicas de compreensão na leitura. A partir da análise dos dados do PIRLS 2016, pode concluir-se que os alunos com meIhores desempenhos frequentam escolas cujos professores «promovem atividades de ensino da leitura que incluem a síntese das ideias principais dos textos lidos" (Marôco, 2018, p. 126). Um bom leitor, de acordo com Sousa (2015, p. 105), "coordena um conjunto flexível de estratégias que mobiliza para responder a situações variadas de leitura. Tenta não perder de vista o objetivo da leitura e vai resolvendo os problemas de compreensão à medida que estes vão surgindo». Por isso, aos professores cabe um papel importantíssimo, ao orientarem os alunos para a utilização de estratégias "em função do tipo de texto, do conhecimento dos alunos e das dificuldades experimentadas pelos alunos» (Morais, 2012, p. 92). Contudo, esse ensino é, segundo Trindade (2009, p. 293), «quase sempre, mínimo e ineficaz, tanto no ensino básico como, principalmente, no secundário, dado que os professores se preocupam exclusivamente com os conteúdos».

Podemos assim concluir que a organização escolar deve ter em conta diversos âmbitos de atuação: a leitura autónoma, a leitura partilhada na sala de aula, a leitura relacionada com os diferentes objetivos curriculares e a leitura orientada pelo docente. A leitura e a escrita devem ser pensadas como parte integrante da aprendizagem em todas as áreas e como recursos para uma estratégia inclusiva para o sucesso educativo e civilizacional.

\section{Iniciação à Leitura e à Escrita: uma resposta a novas necessidades}

A formação inicial de educadores de infância e de professores do $1 .{ }^{\circ}$ e $2 .^{\circ}$ ciclos do Ensino Básico, em Portugal, sofreu profundas alterações na adequação ao Processo de Bolonha.

A unidade curricular (UC) de Iniciação à Leitura e à Escrita foi instituída no contexto dessa adequação, em 2007, integrando conhecimentos relacionados com a aquisição e desenvolvimento da linguagem, a aprendizagem da leitura e da escrita, a formação de leitores para uma Sociedade do Conhecimento, em estreita articulação com a Didática. Por outro lado, esta UC foi também pensada a partir da articulação com as duas UC de Literatura para a Infância da licenciatura.

Teve-se também como horizonte que as instituições de ensino superior devem «asumir un mayor protagonismo en la promoción del hábito lector de sus estudiantes, y (...) activar políticas institucionales para crear espacios y habilitar nuevas oportunidades 
para lograr una mayor vinculación entre la lectura y los tiempos de ocio" (Caride, Caballo, \& Gradaílle, 2018, p. 16). Era esse o enquadramento proporcionado pelo Programa Nacional de Ensino do Português (PNEP) e pelo Plano Nacional de Leitura (PNL), a par da investigação realizada em projetos de doutoramento em Didática que foram determinantes para a criação, a implementação e a atualização da UC de Iniciação à Leitura e à Escrita nos primeiros dez anos.

\section{Práticas pedagógicas em contexto de sala de aula}

Como refere Vieira (2014, p. 15), a forma como aprendemos está intrinsecamente ligada à história que em cada um de nós se vai entretecendo, dando lugar a «(...) um sistema apreciativo (atitudes, predisposições, convicções, representações e expectativas) que atua como um filtro cognitivo e afetivo na interpretação de novas situações de aprendizagem, condicionando o potencial formativo dessas situações». Aos professores, em contexto de sala de aula, cumpre estabelecer um compromisso de respeito mútuo que possibilite a evolução de tais representações, promovendo a participação ativa dos estudantes (Melão, 2017). Nesse sentido, nesta secção do artigo procuramos dar conta dos processos de indagação e sua evolução, fruto do diálogo e da partilha entre professores e estudantes, promovidos ao longo da unidade curricular de Iniciação à Leitura e à Escrita, em três períodos distintos da sua lecionação: i) anos letivos 2009 a 2012; ii) anos letivos 2012-2016; iii) $1 .^{\circ}$ semestre do ano letivo 2018-2019.

A subdivisão apresentada corresponde ao que entendemos enquanto movimentos de indagação/mudança agilizados ao longo das nossas práticas, em função de diferentes reapreciações resultantes da investigação que fomos realizando, em cruzamento com os processos de ensino e aprendizagem. Para cumprir tal objetivo: i) relacionamos, em primeiro lugar, os seus conteúdos programáticos com as abordagens pedagógicas implementadas em contexto de sala de aula, bem como a sua articulação com o trabalho autónomo dos estudantes; ii) indagamos o contributo da literatura para a infância, mormente do livro-álbum, no seu cruzamento com os conteúdos programáticos da unidade curricular relativos à leitura, entrelaçando-os, sempre que tal se afigure pertinente, com a educação literária (e os fios condutores de leituras partilhadas com os estudantes).

\subsection{Conteúdos programáticos e seus entrelaçamentos - que práticas renovar?}

A primeira reestruturação do plano de estudos da licenciatura em Educação Básica propiciou o aumento da carga horária da UC de Iniciação à Leitura e à Escrita, tendo sido feitos os reajustamentos necessários no âmbito da articulação dos seus conteúdos programáticos (embora fosse mantido, sempre, o seu cariz teórico-prático). 
Em 2009, os objetivos da unidade curricular, com uma carga horária semanal de três horas teórico-práticas, contemplavam: i) potenciar a aquisição do saber teórico e técnico necessários à organização fundamentada das atividades de ensino-aprendizagem da leitura e da escrita; ii) desenvolver aprendizagens fomentando métodos de estudo (pesquisa, organização, tratamento e produção da informação); iii) elaborar projetos e materiais no sentido de desenvolver nos futuros alunos as competências relativas à compreensão do oral, expressão oral, leitura, expressão escrita e conhecimento explícito. No que respeita às metodologias de ensino e aprendizagem, estas estavam centradas em dois parâmetros principais, de cariz global: i) leitura e análise de textos de referência (fichas de leitura); ii) criação de materiais. Tais metodologias eram articuladas com três momentos de avaliação: i) prova de avaliação de conhecimentos (individual); ii) trabalho em grupo; iii) trabalho individual.

A orientação da unidade curricular em torno de 4 eixos principais (Oralidade, Leitura, Escrita e Conhecimento explícito da língua), de acrescida complexidade face ao tempo disponível, colocava alguns desafios aos estudantes, mormente relacionados: i) com a morosidade implicada na leitura e análise de textos de referência, exibindo, muitos deles, dificuldades no âmbito do desenvolvimento da compreensão na leitura; ii) com reconhecida falta de consolidação de práticas de leitura por prazer; iii) com a preferência por modalidades de trabalho de cariz individual que, por vez, obstaculizavam posicionamentos críticos fundados no saber fazer em conjunto, reconstruindo conhecimentos. Assim, nos dois anos letivos subsequentes, foram introduzidos itinerários renovados de indagação, construídos em diálogo com os estudantes, contemplando: i) modalidades de trabalho em grupo e a pares, procurando incrementar a sua autonomia, através do estabelecimento de pontes entre o trabalho realizado em contexto de sala de aula e o seu trabalho autónomo; ii) práticas de leitura que estimulassem o desenvolvimento da compreensão da leitura dos estudantes, através da diversificação dos modos/géneros textuais explorados em contexto de sala de aula; iii) avaliação, faseada, do trabalho progressivamente desenvolvido, acolhendo o feedback dos estudantes e procedendo, sempre que necessário, à renegociação da mesma.

De modo a compreendermos, de forma aprofundada, as representações da leitura dos estudantes futuros profissionais da Educação e de que modos se poderiam repercutir nas suas futuras práticas educativas, planificamos e implementamos, durante quatro semanas, ao longo da unidade curricular de Iniciação à Leitura e à Escrita, com 53 estudantes inscritos, a seguinte intervenção didática, sucintamente apresentada no Quadro 1. 
Quadro 1 - Intervenção realizada no âmbito da unidade curricular de Iniciação à Leitura e à Escrita (ano letivo de 2012-2013)

\begin{tabular}{|c|c|c|}
\hline Semanas & $\begin{array}{c}\text { Conteúdos } \\
\text { programáticos }\end{array}$ & Atividades (estudantes) \\
\hline Semana 1 & Conceito de leitura & $\begin{array}{l}\text { - Preenchimento de um questionário, } \\
\text { contemplando os seus dados pessoais, o seu } \\
\text { percurso académico e aspetos relativos às suas } \\
\text { representações sobre a leitura. }\end{array}$ \\
\hline Semana 2 & $\begin{array}{l}\text { Princípios didáticos de } \\
\text { abordagem da iniciação } \\
\text { à leitura }\end{array}$ & $\begin{array}{l}\text { - Trabalho escrito individual de reflexão sobre } \\
\text { o seu futuro público e práticas educativas a } \\
\text { adotar no domínio da leitura; } \\
\text { - Trabalho em grupo, incluindo, numa primeira } \\
\text { fase, a seleção do nível de escolaridade para o } \\
\text { qual o grupo pretende trabalhar (crianças a } \\
\text { iniciar a leitura/Educação Pré-Escolar ou } 1 .^{\circ} \\
\text { ano, crianças em aprofundamento de } \\
\text { competências de leitura/restantes anos do } 1 .^{\circ} \\
\text { CEB e do } 2{ }^{\circ} \text { CEB); } \\
\text { - Análise de documentos sobre estratégias } \\
\text { didáticas de motivação para a leitura e de } \\
\text { desenvolvimento da compreensão na leitura } \\
\text { (com exemplos de atividades; disponibilizados } \\
\text { no Moodle). }\end{array}$ \\
\hline Semana 3 & Modalidades de leitura & $\begin{array}{l}\text { - Seleção de um livro-álbum/obra a trabalhar e } \\
\text { justificação da escolha feita (por escrito - texto } \\
\text { individual); } \\
\text { - Construção de atividades para exploração do } \\
\text { texto selecionado (contemplando as vertentes } \\
\text { da motivação para a leitura e do } \\
\text { desenvolvimento da compreensão na leitura) e } \\
\text { sua fundamentação. }\end{array}$ \\
\hline Semana 4 & $\begin{array}{l}\text { Motivação para a leitura } \\
\text { e desenvolvimento da } \\
\text { compreensão na leitura }\end{array}$ & $\begin{array}{l}\text { Apresentação e discussão das atividades } \\
\text { construidas pelos grupos. }\end{array}$ \\
\hline
\end{tabular}

Da intervenção realizada resultou a reconstrução do perfil de leitor destes estudantes, muito vinculado às práticas de leitura que teriam desenvolvido ao longo do seu percurso académico, em contexto escolar, com os professores, declarando, a maioria, gostar de ler (embora dez estudantes tivessem abertamente declarado não gostar, sendo o navegar na internet o seu passatempo favorito). O cruzamento dos conteúdos programáticos da unidade curricular com a investigação realizada, bem como a sua articulação com modalidades de trabalho individual e em grupo, possibilitou aos estudantes a obtenção de um feedback contínuo e muito atento sobre a necessidade de multiplicar espaços e tempos de reflexão que promovessem o reequacionar de estratégias de desenvolvimento da compreensão na leitura, ecoando nas suas práticas de leitura, bem como no modo como as operacionalizariam com o seu futuro público.

Na medida em que muitos estudantes foram revelando, ao longo da unidade curricular, dificuldades em estabelecer um posicionamento crítico relativamente aos conteúdos 
programáticos abordados, procuramos, nos anos letivos subsequentes, introduzir outras modalidades de trabalho (a pares, por exemplo), incentivando, igualmente, os estudantes a tomar parte em processos de indagação, a nível individual e coletivamente, que permitissem dar voz à sua participação mais ativa e dinâmica. De tal processo resultou, por exemplo, a abordagem que explicitaremos na secção seguinte.

\subsection{Literatura para a infância - como escutar a imaginação e os silêncios?}

Por razões que se prendem com o caráter sintético desta reflexão, nesta subsecção focamos, em síntese, as práticas pedagógicas realizadas no $1 .{ }^{\circ}$ semestre do ano letivo 2018/2019, procurando apresentar a articulação das modalidades de trabalho levadas a cabo com os 43 estudantes do $3 .^{\circ}$ ano da licenciatura em Educação Básica, com os conteúdos programáticos relativos à leitura, tendo como fulcro o livro-álbum (em diálogo com os procedimentos de avaliação renegociados ao longo da UC). No Quadro 2, apresentamos tal articulação, ecoando as suas redefinições e espelhando as inquietações que nos moveram.

Quadro 2 - Abordagem pedagógica realizada relativamente ao conteúdo programático consagrado à leitura

\begin{tabular}{|c|c|c|c|}
\hline \multicolumn{4}{|c|}{ Descrição da abordagem pedagógica } \\
\hline Conteúdos programáticos & Atividades & $\begin{array}{l}\text { Modalidades } \\
\text { de trabalho }\end{array}$ & Avaliação \\
\hline $\begin{array}{l}\text { Leitura } \\
\text { - Conceitos em } \\
\text { desdobramento e sua } \\
\text { multidimensionalidade); } \\
\text { - Estratégias de } \\
\text { desenvolvimento da } \\
\text { compreensão na leitura. } \\
\text { - álbum narrativo, } \\
\text { álbum poético, } \\
\text { etc.; } \\
\text { riqueza e } \\
\text { diversidade dos } \\
\text { elementos } \\
\text { paratextuais } \\
\text { † } \\
\text { Releituras da } \\
\text { reconceptualização } \\
\text { anterior } \\
\text { Representações dos } \\
\text { estudantes sobre o livro- } \\
\text { álbum (evolução) }\end{array}$ & $\begin{array}{l}\text { - Análise de } \\
\text { artigos científicos } \\
\text { centrados no } \\
\text { conceito de } \\
\text { leitura; } \\
\text { - Discussão ampla } \\
\text { do conceito (em } \\
\text { articulação com a } \\
\text { pesquisa dos } \\
\text { estudantes sobre a } \\
\text { mesma temática); } \\
\text { - Comentário } \\
\text { critico dos fílmes } \\
\text { "Os fantásticos } \\
\text { livros-voadores } \\
\text { do Sr. Morris } \\
\text { Lessmore» e de } \\
\text { «A maior flor do } \\
\text { mundo» (José } \\
\text { Saramago); } \\
\text { - Exploração de } \\
\text { livros-álbum - } \\
\text { análise da } \\
\text { interação } \\
\text { imagem/texto. }\end{array}$ & $\begin{array}{l}\text { Trabalho em } \\
\text { grupo ( } 3 \\
\text { fases; sala de } \\
\text { aula/trabalho } \\
\text { autónomo } \\
\text { dos } \\
\text { estudantes) }\end{array}$ & $\begin{array}{l}\text { - Redefinida após cada } \\
\text { fase do trabalho em } \\
\text { grupo, em articulação } \\
\text { com o trabalho a } \\
\text { pares, após o feedback } \\
\text { dos estudantes, em } \\
\text { diálogo com a } \\
\text { docente; } \\
\text { - Apresentação oral } \\
\text { (grupo); comentário } \\
\text { critico e feedback da } \\
\text { docente e dos } \\
\text { estudantes; } \\
\text { - Trabalho escrito } \\
\text { (com propostas de } \\
\text { projetos tendo como } \\
\text { objetivo a motivação } \\
\text { para a leitura - } \\
\text { seleção do nivel de } \\
\text { escolaridade e do ano } \\
\text { letivo por parte dos } \\
\text { estudantes). }\end{array}$ \\
\hline \multicolumn{4}{|c|}{$\begin{array}{l}\text { Fruição na leitura } \\
\text { nto da sensibilidade estética } \\
\text { da imaginação e da curiosidade }\end{array}$} \\
\hline
\end{tabular}


A redescoberta do conceito de leitura, aliado à literacia da leitura e à sua crescente importância na sociedade atual, possibilitou aos estudantes olhar, de forma renovada, as suas práticas de leitura e de escrita, convocando, por vezes, outros olhares advindos do seu percurso na Iniciação à Prática Pedagógica III, unidade curricular que, concomitantemente, concorre para que tenham, em escolas do $1 .^{\circ}$ Ciclo do Ensino Básico, contacto com práticas educativas que muito enriquecem a sua perspetiva sobre as mesmas. A modalidade de trabalho a pares possibilitou, também, o incremento de vias de indagação sobre os seus modos de ler, cinzelando pontos de vista sobre a necessidade de se posicionarem criticamente face aos mundos que os rodeiam.

O livro-álbum revelou-se fundamental no que diz respeito ao fascínio pelo objeto livro, quer pela diversidade de exemplares manuseados - facultados pela docente e comentados, com tempo, em contexto de sala de aula - quer, sobretudo, pela exploração da relação texto/imagem e os percursos que daí emergiram. Acompanhamos, assim, a literatura de especialidade focando a relevância central do livro-álbum para instaurar modos de comunicação inusitados e cada vez mais versáteis, relembrando, com Nodelman (2017) que os livros-álbum «(...) imply an adult reader sharing a text with a younger listener/viewer: they invite an intimate experience of contact and connection" (Nodelman, 2017, p. 11). Em tal experiência de leitura, os estudantes encontraram, porventura, formas de estimular a curiosidade e a imaginação do seu futuro público, tendo os projetos que planificaram para distintos níveis de ensino e anos de escolaridade das suas preferências sido, também, modos de acolher partilhas, no âmbito dos trabalhos em grupo apresentados e discutidos em conjunto. Inferimos que as suas representações sobre o livro-álbum teriam igualmente evoluído, ficando indelevelmente impressas no entusiasmo manifestado.

Desta demanda nasceram novas interrogações relativas, por exemplo, ao modo de criar itinerários multifacetados na UC de Iniciação à Leitura e à Escrita, em cruzamento com outras UC no âmbito das quais o livro-álbum possa propiciar o desenvolvimento da imaginação, preparando os estudantes para reinventarem modos de acolher os desafios de que vão tecendo os seus quotidianos.

No que diz respeito à motivação para a leitura, foi possível inferirmos, através das apresentações orais dos trabalhos em grupo, que os estudantes, a nível pessoal, gostariam de ter mais tempo para ler com fins recreativos, entendendo tal como relevante para a sua futura profissão. Nesse sentido, repensar abordagens pedagógicas que possam incorporar tal desafio instituiu-se enquanto modo de reiniciar caminhos, conjugando modalidades de trabalho articuladas com a avaliação que possibilitem fruir, de forma tão plena quanto precária, outras leituras. 


\section{Considerações finais}

No final dos itinerários de reflexão aqui propostos, importa que nos detenhamos no que "desaprendemos" e "aprendemos" ao longo deste percurso, relativamente aos ofícios de cidadania em que participamos em conjunto, entrelaçados com as práticas pedagógicas implementadas. Um dos aspetos fundamentais que nos parece digno de nota diz respeito ao modo como reaprendemos a escutar os estudantes: os seus modos de ler e de ver os mundos que os rodeavam associados aos desafios que, a par e passo ganhavam voz nas suas vozes, instituíram-se enquanto fonte perene para "desaprender» e "aprender», de novo. Conjugamos, com os estudantes, os tempos e modos verbais do verbo "ser», como pontos de partida para viagens outras que, desejavelmente, os seus futuros profissionais resguardam.

Nas dimensões «inefáveis» da pedagogia que tão bem desenha Vieira (2009), nelas acolhendo o caráter plural dos afetos, encontramos ensejo para esboçar itinerários que mais não são do que inícios que trazem no seu seio a promessa de novos desafios. Procuramos, ao longo dos nossos percursos, que as práticas educativas partilhadas dessem amparo para crescer, de modo a poder abraçar o inusitado, num singular que fez plural.

Face aos múltiplos desafios com que todos os dias nos deparamos, lançar palavras sobre itinerários futuros e sobre os modos como poderão ser ultrapassados é tarefa robusta. Em nosso entender, no que diz respeito às múltiplas leituras de mundos que todos somos chamados a realizar, importará que os docentes estimulem a curiosidade e a redescoberta, aliadas ao conhecimento científico rigoroso das matérias abordadas. Para tal, em unidades curriculares cujo cerne seja a leitura e a escrita, entendemos, também, que a literatura para a infância, nos seus múltiplos apelos, terá, nas próximas décadas, um importante papel a desempenhar, sendo necessários estudos empíricos, a nível nacional e a nível internacional que the possam conferir maior visibilidade (e expor a necessidade de nos apoiarmos na sua versatilidade quando repensamos os perfis dos estudantes na atualidade).

Conclui-se, assim, que deve ser reforçada a aposta na investigação sobre as práticas nos diferentes níveis da atuação: educadores (Jardim-de-infância) e professores (Ensino Básico, Ensino Secundário e Ensino Superior). Espera-se que educadores e professores tenham abertura à mudança, aos novos desafios, às novas práticas discursivas, permanentemente atualizados; que vejam a leitura como condição prioritária do sucesso escolar e como instrumento de integração social. Espera-se que sejam bons leitores, capazes de motivar para a leitura.

Que nos seja permitido, para provisoriamente terminar, recorrer ao belíssimo livro-álbum Eu espero... (Cali, 2008): também nós, na delícia de semelhante espera (enviada, em forma de carta, aos leitores, pelo autor e pelo ilustrador da obra, em «correio 
urgente», com afeto) esperamos "crescer», devagar e com vagar, nos tempos que as incertezas do nosso tempo continuarem a brindar-nos, com a certeza nunca atingida de que continuaremos a partilhar desafios reconstruídos, em permanência, com todos os estudantes.

\section{Referências Bibliográficas}

Andrade, E. (2016). Vertentes do olhar. Lisboa: Assírio \& Alvim.

Balula, J. P. (2011). Estratégias de leitura funcional: uma proposta de abordagem didática. In O. C. Sousa, C. Cardoso \& M. Dias (Ed.). Formar professores, investigar práticas. Atas do IV Encontro do CIED (pp. 22-26). Lisboa: Instituto Politécnico de Lisboa - Escola Superior de Educação.

Boavida, J. (2013). Que fundamentos para uma educação em tempo de crise? In M. Formosinho, J. Boavida \& M. L. Damião (Org.) Educação: perspetivas e desafios (pp. 21-33). Coimbra: Imprensa da Universidade de Coimbra.

Bugallo-Rodríguez, Á. \& Naya-Riveiro, M. C. (2018). Educación para la ciudadanía global (ECG): comprendiendo lo internacional a través de lo local. Revista Lusófona de Educação, 41, (41) [Disponível em http://revistas.ulusofona.pt/index.php/rleducacao/article/view/6498, consultado em 27/12/2018].

Cali, D. (2008). Eu espero... Ilustrações de Serge Bloch. Tradução de Miguel Gouveia. Figueira da Foz: Bruáa Editora.

Caride, J. A., Caballo, M. B. \& Gradaílle, R. (2018). Leer en tempos de ocio: los estudiantes, futuros profesionales de la educación, como sujetos lectores. Ocnos, 17 (3), 7-18 [Disponível em https:// revista.uclm.es/index.php/ocnos/article/view/ocnos_2018.17.3.1707, consultado em 8/01/2018].

Colomer, T. (2010). Planificar la lectura en la escuela. In A. Nóvoa, A. J. Teixeira, A. P. López-Casero, E. M. Grilo, F. S. G. Amorim, I. Alçada, J. A. Gomes, J. Barata-Moura, L. Sipe, M. L. Dionísio, M. Nikolajeva, M. Fayol, P. Morão, P. Cerrillo, P. Duran, P. Hunt, S. L. Beckett, T. Colomer, Formar leitores para ler o mundo (pp. 83-93). Lisboa: Fundação Calouste Gulbenkian.

Freire, P. (2002). Pedagogia da autonomia. Saberes necessários à prática educativa, 25. ${ }^{a}$ edição. São Paulo: Editora Paz e Terra.

Hénard, F. \& Roseveare, D. (2012). Fostering quality teaching in higher education: policies and practices. Paris: OECD/Institutional Management in Higher Education [Disponível em https://www.oecd.org/ education/imhe/QT\%20policies\%20and\%20practices.pdf, consultado em 18/11/2018].

Leite, C. \& Ramos, K. (2014). Políticas do Ensino Superior em Portugal na fase pós-Bolonha: implicações no desenvolvimento do currículo e das exigências ao exercício docente. Revista Lusófona de Educação, 28, 73-89 [Disponível em http://revistas.ulusofona.pt/index.php/rleducacao/article/ view/4923, consultado em 21/12/2018].

Maia, C. (2013). Sustentabilidade educativa: circunstância, ideal e singularidade. In M. Formosinho, J. Boavida \& M. L. Damião (Org.) Educação: perspetivas e desafios (pp. 55-76). Coimbra: Imprensa da Universidade de Coimbra. 
Marôco, J. (2018). O bom leitor: preditores da literacia de leitura dos alunos portugueses no PIRLS 2016. Revista Lusófona de Educação, 31(2) 115-131 [Disponível em https://revistas.rcaap.pt/rpe/article/ view/13768, consultado em 8/01/2019].

Melão, D. \& Balula, J. P. (2012). Ler no ecrã: contributo para uma reflexão sobre estratégias de ensino da leitura na aula de Português. Exedra: Revista Científica, N. ${ }^{\circ}$ Extra 6, 229-242 [Disponível em http:// hdl.handle.net/10400.19/1542, consultado em 8/01/2019].

Melão, D. (2017). Périplos textuais e representações da educação literária no ensino básico. Revista Lusófona de Educação, 37, 45-61 [Disponível em https://revistas.ulusofona.pt/index.php/ rleducacao/article/view/6229, consultado em 6/12/2018].

Morais, J. (2012). Criar leitores. O ensino da leitura - para professores e encarregados de educação. Porto: Livpsic.

Nodelman, P. (2017). Introduction: why we need more words. In N. Hamer, P. Nodelman \& M. Reimer (Eds.) More words about pictures. Current research on picture books and visual/verbal texts for young people (pp. 1-17). London and New-York: Routledge.

OECD (2018a). Teaching for the future: effective classroom practices to transform education. Paris: OECD Publishing [Disponível em http://dx.doi.org/10.1787/9789264293243-en., consultado em 6/11/2018].

OECD (2018b). The future of education and skills. Education 2030. Paris: OECD Publishing [Disponível em https://www.oecd.org/education/2030/E2030\%20Position\%20Paper\%20(05.04.2018).pdf, consultado em 5/04/2018].

Ondjaki (2008). Há prendisagens com o xão, 3. ${ }^{a}$ edição. Lisboa: Caminho.

Ramos, A. et al. (2013). Implementação de novas práticas pedagógicas no ensino superior. Revista Portuguesa de Educação, 26 (1), 115-141 [Disponível em https://revistas.rcaap.pt/rpe/article/ view/2986, consultado em 2/11/2018]

Raya, M. J., Lamb, T. \& Vieira, F. (2017). Mapping autonomy in language education: a framework for learner and teacher development. Frankfurt am Main: Peter Lang.

Sá-Chaves, I. (2007). Cultura, conhecimento e identidade. Universidade e contemporaneidade. Saber (e) Educar, 12, 9-28 [Disponível em http://repositorio.esepf.pt/bitstream/20.500.11796/712/2/ SeE12Culturaldalia.pdf, consultado em 2/11/2018].

Sousa, O. C. (2015). Textos e contextos: leitura, escrita e cultura letrada. Porto: Editora Media XXI.

Trindade, M. N. (2009). O ensino e a aprendizagem da compreensão leitora: algumas notas sobre o que está por fazer em Portugal. In J. Bonito (Org.), Ensino, qualidade e formação de professores (pp. 291-307). Évora: Departamento de Pedagogia e Educação da Universidade de Évora.

Vieira, F. (2009). Em contracorrente. O valor da indagação da pedagogia na universidade. Educação, sociedade e culturas, 28, 107-126 [Disponível em http://www.fpce.up.pt/ciie/revistaesc/ESC28/28_ flavia.pdf, consultado em 4/11/ 2018].

Vieira, F. (2014) (Org.). Re-conhecendo e transformando a pedagogia: histórias de supervisão. Santo Tirso: De Facto Editores. 
João Paulo Balula

Escola Superior de Educação de Viseu, Instituto Politécnico de Viseu

Centro de Estudos em Educação e Inovação (Cl\&DEI)

Email: jpbalula@esev.ipv.pt

ORCID: https://orcid.org/0000-0003-1598-1406

Dulce Melão

Escola Superior de Educação de Viseu, Instituto Politécnico de Viseu

Centro de Estudos em Educação e Inovação (Cl\&DEI)

Email: dulcemelao@esev.ipv.pt

ORCID: https://orcid.org/0000-0002-1608-1074

Correspondência

João Paulo Balula

Escola Superior de Educação de Viseu

Rua Maximiano Aragão 3504-501 Viseu-Portugal

Data de submissão: Dezembro 2018

Data de avaliação: Março 2019

Data de publicação: Setembro 2019 